\title{
USE OF SOCIAL INDICES IN PSYCHIATRIC EPIDEMIOLOGY
}

\author{
BY \\ A. E. PHILIP AND J. W. MCCULLOCH \\ Medical Research Council Unit for Research on the Epidemiology of Psychiatric Illness, Edinburgh University Department \\ of Psychiatry, Royal Edinburgh Hospital, Morningside Park, Edinburgh 10
}

In the course of period prevalence studies carried out by members of the Medical Research Council Unit for Research on the Epidemiology of Psychiatric Illness in Edinburgh, it was observed that the rates of illness for the municipal wards showed marked differences. In the study on self-poisoning and self-injury carried out by McCulloch (1965) and Kessel (1965), the prevalence rates were compared with several social characteristics and indices of social disorganization. The findings of this and other related studies have been summarized by Kessel.

In another prevalence study, which investigated the rate of psychiatric referrals in Edinburgh adolescents (McCulloch, Henderson, and Philip, 1966), variations between wards were also found. In this study 19.3 per cent of the cases had, during the year under scrutiny, been referred for psychiatric treatment following acts of self-poisoning or selfinjury. The distribution over city wards for this group of adolescents was similar to the distribution of all acts of self-poisoning and self-injury found by Kessel and McCulloch. The remainder of the adolescent group was distributed in a manner inversely related to the self-poisoners of both studies. The present paper is an attempt to relate these differences to social factors in the environment, using variables which were readily available.

Ecological variables have been used by researchers in other fields to shed light on deviant behaviour, mental disorder and physical illness. Studies of delinquent behaviour here show associations with many adverse social factors, notably overcrowding (Burt, 1944; Stott, 1960, 1962; Ferguson, 1952; Gibbens, 1961; Power, 1965). Social factors in a wide range of physical illnesses have been studied and have influenced legislation affecting diet, accommodation, and treatment (Ferguson, 1948; Reid, 1958; Guerrin and Borgatta, 1965; Lebowitz and Malcolm, 1964). In the field of mental illness there have been innumerable attempts to relate psychiatric disorder and treatment to social factors (Renton, Affleck, Carstairs and Forrest, 1963; Taylor and Chave, 1964; Faris and Dunham, 1939; Dunham, 1959). More generally, in the field of social welfare, specific problems are better understood when ecological variables are considered (Tuckman and Youngman, 1964; Fitzsimmons, 1952; McCulloch, Philip, and Henderson, 1966).

Much of the information which could provide ecological data is routinely collected and reported by various bodies, but unfortunately this is not always available in a uniform, readily comparable manner. To the variables from the two surveys already mentioned, for which city rates by the 23 electoral wards were already calculated, we added fifteen variables, mostly of a social nature, giving the eighteen variables shown in Table I (opposite).

Of the latter fifteen variables, six items were taken from the 1961 Census (General Registry Office, Edinburgh, 1963), seven items were supplied from various departments of the local authority, juvenile delinquency rates were obtained from Jackson (1966), and the R.S.S.P.C.C. figures were collected by one of us (J.W.McC.) from the Society's records. There are other variables which we should have liked to add, notably National Assistance, unemployment, and crime. At present, however, the agencies concerned do not report in a manner conducive to translation into rates for individual wards. For each electoral ward we calculated, for each variable, the rate of incidence for every 1,000 units at risk. On the basis of each of these rates the electoral wards were placed in rank order, the ward with the highest rate being given a rank of 1 and that with the lowest rate a rank of 23. Spearman rank order correlation coefficients $(\rho)$ were calculated between all variables 
TABLE I

RANK ORDER OF 18 SOCIAL VARIABLES BY 23 ELECTORAL WARDS

\begin{tabular}{|c|c|c|c|c|c|c|c|c|c|c|c|c|c|c|c|c|c|c|c|c|}
\hline \multicolumn{3}{|c|}{ Social Variable } & 1 & 2 & 3 & 4 & 5 & 6 & 7 & 8 & 9 & 10 & 11 & 12 & 13 & 14 & 15 & 16 & 17 & 18 \\
\hline Warc & $\begin{array}{l}1 \text { St Giles .. } \\
2 \text { Holyrood . } \\
3 \text { George Square } \\
4 \text { Newington } \\
5 \text { Liberton .. } \\
6 \text { Morningside } \\
7 \text { Merchiston } \\
8 \text { Colinton . . } \\
9 \text { Sighthill . } \\
10 \text { Gorgie/Dalry } \\
11 \text { Corstorphine } \\
12 \text { Murrayfield/Cram } \\
13 \text { Pilton } \\
14 \text { St. Bernard's } \\
15 \text { St. Andrew's } \\
16 \text { Broughton } \\
17 \text { Calton } \\
18 \text { West Leith . } \\
19 \text { Central Leith } \\
20 \text { South Leith } \\
21 \text { Craigentinny } \\
22 \text { Portobello } \\
23 \text { Craigmillar }\end{array}$ & 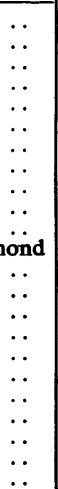 & $\begin{array}{r}9 \\
23 \\
6 \\
7 \\
8 \\
19 \\
4 \\
12 \\
22 \\
16 \\
11 \\
1 \\
21 \\
13 \\
15 \\
17 \\
20 \\
2 \\
14 \\
3 \\
10 \\
5 \\
18\end{array}$ & $\begin{array}{r}7 \\
2 \\
4 \\
12 \\
13 \\
8 \\
14 \\
15 \\
5 \\
17 \\
20 \\
22 \\
21 \\
9 \\
6 \\
18 \\
11 \\
19 \\
1 \\
23 \\
16 \\
10 \\
3\end{array}$ & $\begin{array}{l}1 \\
5 \\
7 \cdot 5 \\
17 \\
10 \\
16 \\
20 \\
19 \\
18 \\
14 \\
23 \\
22 \\
9 \\
13 \\
7 \cdot 5 \\
6 \\
33 \\
12 \\
4 \\
11 \\
21 \\
15 \\
2\end{array}$ & $\begin{array}{r}2 \\
4 \\
11 \\
19 \\
9 \\
22 \\
20 \\
18 \\
6 \\
16 \\
21 \\
23 \\
3 \\
13 \\
7 \\
8 \\
12 \\
10 \\
5 \\
14 \\
15 \\
17 \\
1\end{array}$ & $\begin{array}{r}2 \\
8 \\
7 \\
17 \\
6 \\
23 \\
20 \\
19 \\
16 \\
15 \\
22 \\
12 \\
3 \\
18 \\
11 \\
10 \\
4 \\
9 \\
5 \\
13 \\
21 \\
14 \\
1\end{array}$ & $\begin{array}{r}19 \\
4 \\
1 \\
10 \\
6 \\
19 \\
19 \\
11 \\
8 \\
19 \\
14 \\
7 \\
3 \\
19 \\
19 \\
19 \\
19 \\
12 \\
19 \\
13 \\
5 \\
9 \\
2\end{array}$ & $\begin{array}{r}19 \\
3 \\
1 \\
14 \\
9 \\
19 \\
19 \\
13 \\
10 \\
19 \\
5 \\
7 \\
4 \\
19 \\
19 \\
19 \\
19 \\
8 \\
19 \\
11 \\
6 \\
12 \\
2\end{array}$ & $\begin{array}{r}19 \\
9 \\
1 \\
13 \\
5 \\
19 \\
19 \\
11 \\
7 \\
19 \\
8 \\
6 \\
3 \\
19 \\
19 \\
19 \\
19 \\
10 \\
19 \\
14 \\
4 \\
12 \\
2\end{array}$ & $\begin{array}{r}4 \\
3 \\
17 \\
20 \\
10 \\
23 \\
19 \\
18 \\
11 \\
6 \\
21 \\
22 \\
7 \\
14 \\
5 \\
13 \\
8 \\
15 \\
2 \\
9 \\
12 \\
16 \\
1\end{array}$ & $\begin{array}{c}3 \\
6 \\
15 \\
20 \cdot 5 \\
7 \\
20 \cdot 5 \\
20 \cdot 5 \\
13 \\
10 \\
20 \cdot 5 \\
20 \cdot 5 \\
11 \\
5 \\
9 \\
1 \\
17 \\
8 \\
14 \\
2 \\
20 \cdot 5 \\
16 \\
12 \\
4\end{array}$ & $\begin{array}{c}18 \cdot 5 \\
1 \\
23 \\
10 \cdot 5 \\
17 \\
15 \cdot 5 \\
15 \cdot 5 \\
8 \cdot 5 \\
10 \cdot 5 \\
3 \cdot 5 \\
21 \\
12 \\
14 \\
18 \cdot 5 \\
5 \\
22 \\
13 \\
6 \cdot 5 \\
6 \cdot 5 \\
20 \\
3 \cdot 5 \\
8 \cdot 5 \\
2\end{array}$ & $\begin{array}{r}3 \\
13 \\
20 \\
7 \\
8 \\
16 \\
1 \\
23 \\
18 \\
12 \\
14 \\
17 \\
5 \\
15 \\
10 \\
19 \\
21 \\
6 \\
22 \\
9 \\
2 \\
11 \\
4\end{array}$ & $\begin{array}{r}17 \\
15 \\
6 \\
8 \\
19 \\
1 \\
2 \\
12 \\
21 \\
14 \\
3 \\
5 \\
22 \\
13 \\
20 \\
7 \\
9 \\
4 \\
16 \\
10 \\
18 \\
11 \\
23\end{array}$ & $\begin{array}{r}14 \\
15 \\
19 \\
10 \\
3 \\
23 \\
21 \\
7 \\
4 \\
13 \\
12 \\
9 \\
2 \\
8 \\
22 \\
17 \\
20 \\
11 \\
18 \\
16 \\
5 \\
6 \\
1\end{array}$ & $\begin{array}{r}2 \\
3 \\
8 \\
14 \\
23 \\
17 \\
10 \\
18 \\
16 \\
4 \\
12 \\
22 \\
15 \\
13 \\
5 \\
9 \\
6 \\
11 \\
1 \\
7 \\
21 \\
19 \\
20\end{array}$ & $\begin{array}{r}6 \\
9 \\
2 \\
5 \\
22 \\
8 \\
1 \\
18 \\
21 \\
12 \\
17 \\
16 \\
20 \\
7 \\
1 \\
3 \\
4 \\
13 \\
10 \\
14 \\
19 \\
15 \\
23\end{array}$ & $\begin{array}{r}13 \\
8 \\
3 \\
4 \\
21 \\
1 \\
2 \\
19 \\
20 \\
11 \\
16 \\
17 \\
23 \\
14 \\
9 \\
6 \\
7 \\
5 \\
15 \\
10 \\
12 \\
18 \\
22\end{array}$ & $\begin{array}{r}2 \\
8 \\
13 \\
16 \\
7 \\
19 \\
22 \\
17 \\
15 \\
14 \\
23 \\
20 \\
3 \\
12 \\
4 \\
11 \\
6 \\
10 \\
5 \\
18 \\
21 \\
9\end{array}$ \\
\hline
\end{tabular}

Social Variable 1 =Adolescent psychiatric referral $2=$ Adolescent self-poisoning and self-injury $3=$ All ages self-poisoning and self-injury $4=$ Juvenile delinquency $5=$ Children taken into care $6=$ Eviction notices $7=$ Peace warnings $8=$ Rent arrears

$9=$ Overcrowding ( $>1.5$ persons per room)

and the resultant correlation matrix appears in Table II.

While these correlation coefficients indicate the degree of association between any two variables, further procedures are necessary to elicit more complex relationships. In this instance we used a typal method as opposed to the more common technique of factor analysis.

The particular method we have used to treat our
$10=$ School absences (for reasons other than sickness)

$11=$ Infant mortality

$12=$ Stillbirths

$13=$ Owner-occupied houses

$14=$ Council houses

$15=$ Private unfurnished houses

$16=$ Private furnished houses

$17=$ Old age pensioners

$18=$ R.S.S.P.C.C. referrals

table of intercorrelated variables is that of Elementary Linkage Analysis, developed by McQuitty (1957, 1961, 1964) as a rapid and objective method for clustering variables into types. These variables can be people, items, or other objects; in the present case they are mainly social variables. Elementary Linkage Analysis defines the linkage between two items as being the largest index of association which a variable has with any of the other variables. Every

TABLE II

SPEARMAN $\rho$ CORRELATIONS BETWEEN 18 SOCIAL VARIABLES

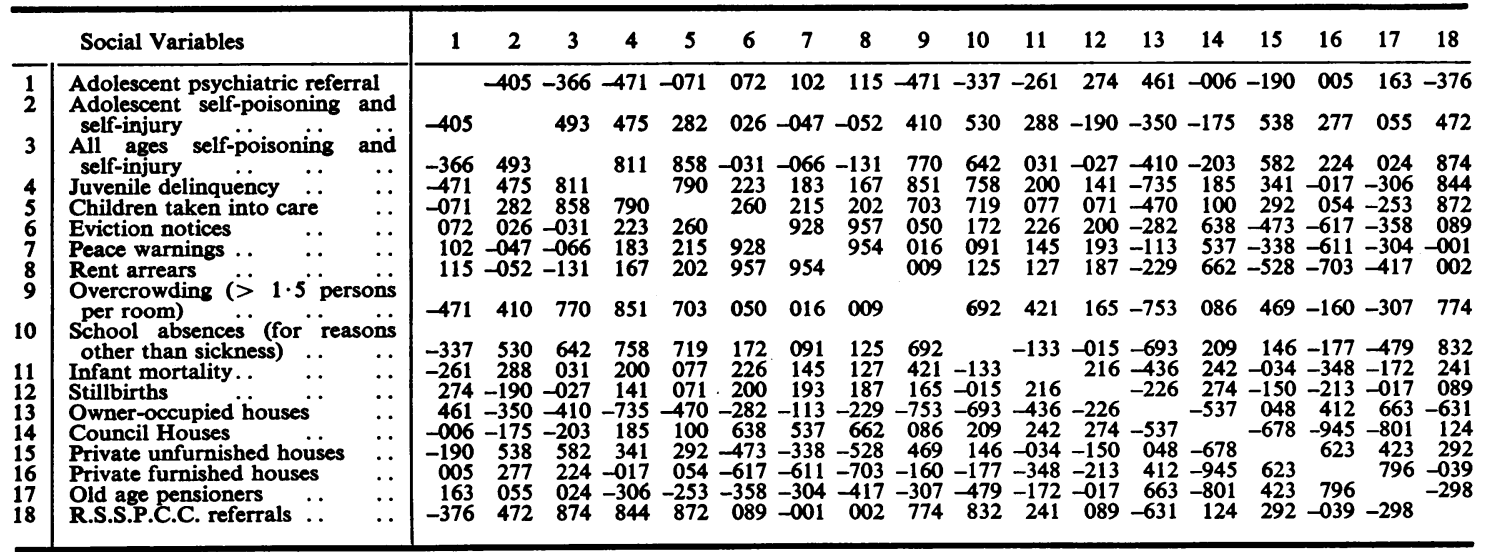


variable is assigned to a cluster in terms of its highest index of association, usually a form of correlation coefficient.

Cluster methods are related to typal theory, which in general states that every member of a type is more like some other member of that type than any member of any other type. Within the bounds of typal theory, McQuitty has developed various clustering methods of which Elementary Linkage Analysis, as its name might suggest, is the simplest. Its underlying rationale is essentially the same as for more sophisticated methods, while its simplicity and ease of calculation lend it well to data of this nature.

The procedure involved in Elementary Linkage Analysis starts with the correlation matrix (Table II) and consists of five steps;

(i) Underline the highest entry in each column of the matrix.

(ii) Select the highest entry of the entire matrix; the two variables having this correlation constitute the first two variables of the first cluster (see Figure).

(iii) Select all those variables which are most like the variables of the first cluster. Do this by reading along the rows of the variables which emerged in Step 2 and selecting any underlined coefficients in these rows. The Figure indicates the manner in which these new cluster members are related to the original pair.

(iv) Select any variables which are most like the variables elicited in Step 3. Repeat the procedure of Step 3 until no further variables emerge.

(v) Excluding all those variables which fall within Cluster 1, repeat Steps 2 to 4.

\section{Results}

Using Elementary Linkage Analysis, four clusters emerged from the correlation matrix. These are set out in the Figure. Cluster 1 relates Eviction Notices, Peace Warnings (or final warnings about arrears of rent), and Rent Arrears. Cluster 2 brings together all types of accommodation except Owner-occupied Houses and shows that Old Age Pensioners are less frequently found in Council Houses. Low rates of Adolescent Self-poisoning are seen to be associated with low rates of Private Rented Unfurnished Accommadation. In Edinburgh this means prefirst world war tenement buildings, usually of a low standard. Although Stillbirths are seen to be related

LINKAGE ANALYSIS OF VARIABLES

\begin{tabular}{|c|c|}
\hline \multicolumn{2}{|r|}{$\begin{array}{l}\text { Ih Rate of Rent Arrears } \\
\text { Many Peoce Wornings }\end{array}$} \\
\hline $\begin{array}{l}\text { CLUSTER } 2 \\
\text { Few Prive }\end{array}$ & $\begin{array}{l}\text { Homes }(16) \rightleftharpoons \text { (12) Many Stillbirths } \\
\text { (14) Many Local Authority Homes }-1(17) \text { Few Old-age Pensioners } \\
\text { (15) Few Private Unfurnished Homes } \\
\text { (2) Low Rate of Adolescent Self-Poisoning }\end{array}$ \\
\hline $\begin{array}{l}\text { CLUSTER } 3 \\
\text { High Rate }\end{array}$ & $\begin{array}{l}\text { (5) Many Children in Core } \\
\text { oisoning (3) (18) Many R.S.S.P.C.C. Coses } \\
\text { (10) Many School Absences }\end{array}$ \\
\hline $\begin{array}{r}\text { CLUSTER } 4 \\
\text { Much }\end{array}$ & $\begin{array}{l}\text { (12) Many Stillbirths } \\
\text { (13) Few Owner-occupied Homes } \\
\text { (iil) High Infant Mortality Rate }\end{array}$ \\
\hline
\end{tabular}

$\rightleftharpoons$ denotes a reciprocal relationship between two variables.

$\rightarrow$ denotes that a variable at the tail of the arrow has its highest correlation with the variable at the head of the arrow. FIGURE.-Four clusters derived from Elementary Linkage Analysis. 
to Council Housing, the small numbers involved make this an unreliable variable. Cluster 3 associates All Self-poisoning and Self-Injury to three variables clearly concerned with a very special kind of parentchild relationship involving separation and trauma. Cluster 4 shows a positive relationship between Juvenile Delinquency and Overcrowding. Both these variables are negatively related to Adolescent Psychiatric Referral. Not surprisingly, Overcrowding is negatively related to Owner-occupied Houses. Both Stillbirths and Infant Mortality fall within this cluster, but again the lack of variance in these rates makes them unreliable.

\section{Discussion}

In research which is centred in large groups of people, whether in physical medicine, psychiatry, or sociology, the tendency has been for each researcher to go his own way, defining his variables in terms of his theoretical orientation and training. Descriptions of unfavourable environment such as "broken homes" and "overcrowding"; designations of personalities such as "inadequate", "abnormal", or "deviant" are commonplace. Often, such studies cause more confusion than enlightenment because of their use of idiosyncratic categories which defy attempts at replication. The present method makes use of readily available, replicable information which, although based on impersonal data, can provide testable hypotheses by eliciting associations which might otherwise be overlooked. Other researchers (Burt, 1944; Guerrin and Borgatta, 1965) have utilized the availability of this kind of data and, like ourselves, have studied their variability over city wards. Burt, in his classic book "The Young Delinquent", was content to correlate each of his variables with juvenile delinquency, pointing out as he did so that despite all their crudity and shortcomings they were remarkably consistent. Guerrin and Borgatta (1965) correlated a large number of variables derived in the main from the U.S. Census and used factor analysis to form groups of related variables. One purpose of this paper is to demonstrate the use of readily available material as a prelude to more detailed investigation. Factor analysis is a laborious procedure when electronic computing facilities are not available. Elementary Linkage Analysis, on the other hand, is simple and rapid once the correlations between items have been calculated. The clusters which emerge form a statistically unique solution for the variables under scrutiny, while factors in factor analysis have generally to be manipulated (rotated) to make them meaningful.
Clusters 1 and 2 (Figure) demonstrate the way in which like variables cohere. Clusters 3 and 4 show how items which might not have been thought to be associated fall together into types. Cluster 3 demonstrates especially well the value of Linkage Analysis. While much research has been carried out in Edinburgh on acts of self-poisoning, self-injury, and suicide, no association between these acts and the other three variables in the cluster has been considered before. Disturbances in childhood were noted in these studies but now it can be seen that further, more detailed research should be carried out. This is now under way. Kessel (1965) and McCulloch (1965) in their 1962-3 survey found that people who poisoned or injured themselves were, in the vast majority of cases, acting impulsively. McCulloch, Philip, and Henderson (1966) have pointed out that parents who keep their children absent from school often do so for no considered reason, in other words they too are behaving impulsively. Clearly there is a strong case to be made for investigating, in individual cases, the relationships shown by this cluster. If, for example, it could be shown that an identifiable group of cruelly-treated children ultimately attempted to take their lives, preventive measures could be undertaken.

Not surprisingly, Cluster 4 shows the well known relationship between Juvenile Delinquency and Overcrowding but it has also highlighted the negative relationship between these two variables and psychiatric referrals in adolescence. Again this cluster acts as a starting point for further research.

In Elementary Linkage Analysis clusters are not necessarily unrelated; indeed in the present instance there are many significant correlations between items which cut across types. For example, Adolescent Self-Poisoning correlates highly with All SelfPoisoning $(\rho=493)$, while the latter correlates $(\rho=811)$ with Juvenile Delinquency. This can be used in addition to the relationships shown in the clusters and, if necessary, the typal relationships between the clusters can be calculated, yielding second order types (McQuitty, 1957, 1961). A further point is that when collecting data of this kind the number of variables can increase alarmingly. Typal analysis allows us to cope with this situation by selecting from each type or cluster one or more variables which best represent that type. In the Figure we could select Rent Arrears alone to represent the social situation reflected in all three variables of Cluster 1. By this method it is possible to handle material which otherwise would become unwieldy. 


\section{SUMmaRY}

The relationship between social factors in the environment and deviant behaviour, mental disorder, and physical illness has been discussed. Elementary Linkage Analysis has been used to show which of eighteen social and psychiatric variables cluster together. The advantages of this method have been discussed with special emphasis on the formulation of hypotheses for future research.

We are indebted to Mr. N. Jackson, the R.S.S.P.C.C., and various Departments of Edinburgh Corporation for making data available. Thanks are due to Prof. G. M. Carstairs for his helpful advice.

\section{REFERENCES}

Burt, C. (1944). "The Young Delinquent", 4th ed. University of London Press, Bickley, Kent.

Dunham, H. W. (1959). "Sociological Theory and Mental Disorder". Wayne State University Press, Detroit.

Faris, R. E. L., and Dunham, H. W. (1939). "Mental Disorder in Urban Areas". University of Chicago Press, Chicago.

Ferguson, T. (1948). "The Dawn of Scottish Social Welfare". Nelson, London and Edinburgh.

- (1952). "The Young Delinquent in his Social Setting: A Glasgow Study" (Nuffield Foundation). Oxford University Press, London.

Fitzsimmons, M. (1952). "Indebtedness as a Casework Problem". Paper read at the National Conference of Social Work, Chicago.
General Registry Office, Edinburgh (1963). Census 1961. Scotland. County Report. Vol. 1, Part 1. City of Edinburgh.

Gibbens, T. C. N. (1961). "Trends in Juvenile Delinquency". Publ. Hlth Papers, No. 5. World Health Organization, Geneva.

Guerrin, R. F., and Borgatta, E. F. (1965). Milbank Mem. Fund Quart., 43, 269.

Jackson, N. (1966). Private communication.

Kessel, N. (1965). Brit. med. J., 2, 1265, 1336.

Lebowitz, M. D., and Malcolm, J. C. (1964). Amer. J. publ. Hlth, 54, 1876.

McCulloch, J. W. (1965). "The Social Consequences of Acts of Deliberate Self-Poisoning and Self-Injury". Edinburgh University Library (unpublished M.Sc. dissertation).

, Henderson, A. S., and Philip, A. E. (1966). "Patterns of Psychiatric Illness in Teenagers". Paper read to the Scottish Psychiatric Research Society, Glasgow. , Philip, A. E., and Henderson, A. S. (1966). Scot. educ. J. (In press).

McQuitty, L. L. (1957). Educ. psychol. Measur., 17, 207. - (1961). Ibid., 21, 677.

- (1964). Ibid., 24, 441.

Power, M. J. (1965). Proc. roy. Soc. Med., 58, 704.

Reid, D. D. (1958). Lancet, 1, 1237, 1289.

Renton, C. A.. Affleck, J. W., Carstairs, G. M., and Forrest, A. D. (1963). Acta psychiat. scand., 39, 548.

Stott, D. H. (1960). Brit. J. Psychol., 51, 157. (1962). Brit. J. soc. clin. Psychol., 1, 182.

Taylor, Lord, and Chave, S. (1964). "Mental Health and Environment". Longmans, London.

Tuckman, J., and Youngman, W. F. (1964). J. genet Psychol., 105, 187. 
most reliable body of data I could find I read Backman's (1948) review with care and consulted every one of the several hundred references cited that I could find. Many of the data Backman refers to are statistically very poor and some reports include previous series. None can be used without a critical look at the originals. It appears that Brown did not spot Backman's miscalculation of the mean in one of the earlier English references, and why did he count Robertson's cases in twice? Why, too, did he in his Fig. 3 plot data relating to approximately 1913 at 1933 for graphic comparison with data relating to 1949 plotted at 1949 ? When I first plotted the results from the data I assembled, I certainly had no particular view of the matter.

It seems that Brown's distortion of my views may come at base from his curious concept of biology. He writes:

"If Tanner (1961) believes "the secular trend . . . is one of the most considerable phenomena of human biology at present ... . and has a host of medical, educational, and sociological consequences', then it must be admitted that no comparable phenomenon readily comes to mind that is not the outcome of a prolonged evolutionary process".
May I suggest a few thoughts to fill the blank? Family planning for instance, and the trend toward smaller families; or migration both within and without countries: other examples may be found in a text book of "Human Biology" (Harrison, Weiner, Tanner, and Barnicot, 1964). To Brown, biology seems to exclude the environment, nutrition, disease, and so forth-in other words the warp of the subject. This is an old-fashioned view and one from which I most emphatically dissociate myself.

\section{REFERENCES}

Backman, G. (1948). Acta anat. (Basel), 4, 421

Brown, P. E. (1966). Brit. J. prev. soc. Med., $20,9$.

Harrison, G. A., Weiner, J. S., Tanner, J. M., and Barnicot, N. A. (1964). "Human Biology". Clarendon Press, Oxford.

Tanner, J. M. (1961) "Education and Physical Growth". University of London Press.

(1962). "Growth at Adolescence", 2nd ed. Blackwell, Oxford.

(1965). "The Trend towards Earlier Physical Maturation", in "Biological Aspects of Social Problems", ed. J. E. Meade and A. S. Parkes, pp. 40-65. (Eugenics Society Symposia, vol. 1). Oliver and Boyd, Edinburgh.

\section{CORRECTION}

In the article by A. E. Philip and J. W. McCulloch (Brit. J. prev. Soc. Med., 1966, 20, 122) in Table I, the Rank Order for Variable 16, Ward 7, should read 11 (not 1 as printed). 